\title{
Developing Regional Tephrochronological Frameworks for Testing Hypotheses of Synchronous Climate Change
}

\section{C.S.M. TuRNeY ${ }^{1 *}$, S.M. DaVIES ${ }^{2}$, and B.V. AllowaY ${ }^{3}$}

${ }^{1}$ GeoQuEST Res. Centre, School of Earth and Env. Sciences, Univ. of Wollongong, Wollongong NSW 2522, Australia; turney@uow.edu.au ${ }^{2}$ Department of Geography, University of Wales Swansea, Singleton Park, Swansea, SA2 8PP, Wales, U.K.

${ }^{3}$ Institute of Geological \& Nuclear Sciences (GNS), Wairakei Research Centre, Private Bag 2000, Taupo, New Zealand

*INQUA Sub-Commission for Tephrochronology and Volcanism (SCOTAV)

A key issue in paleoclimatic research is establishing the precise rate and mode of climate response in different parts of the world to abrupt changes in global climate. Crucial to the success of this research is the development of robust regional tephrochronological frameworks. Tephrochronology provides timeparallel marker horizons that allow precise correlation between environmental and climatic records of the recent geological past (Turney and Lowe, 2001). Few (if any) geochronological techniques can provide the precision offered by tephrochronology. The virtually instantaneous atmospheric deposition of tephra following an eruption can often lead to clear tephra layers in a wide range of depositional environments. SCOTAV is dedicated to identifying the global distribution of tephra for a wide range of multi-proxy studies. Nowhere is this more relevant than in the application to studies of past rapid climate change.

As an example of the potential to climate studies, it has long been recognized that in the North Atlantic region, a sequence of abrupt climate changes can be identified through the Last Termination (18-9 ka ${ }^{14} \mathrm{C} \mathrm{BP}$ ), including rapid warming at 14.7 ka GRIP ice-core years BP ("Bølling" Interstadial, or Gl-1 in the Greenland ice-core isotope stratigraphy) and the sustained cooling of the Younger Dryas Stadial (GS-1; 12.8 to 11.5 ka GRIP ice-core yrs BP) (Lowe et al., 2001; Fig. 1). Since 1997, INTIMATE (INTegration of Ice, MArine and TErrestrial records) is a core program of INQUA. Paleoclimate Commission project members have, through a series of international workshops, sought ways to improve procedures for establishing the precise ages of, and effecting high-resolution correlations between, events during this period. With the development

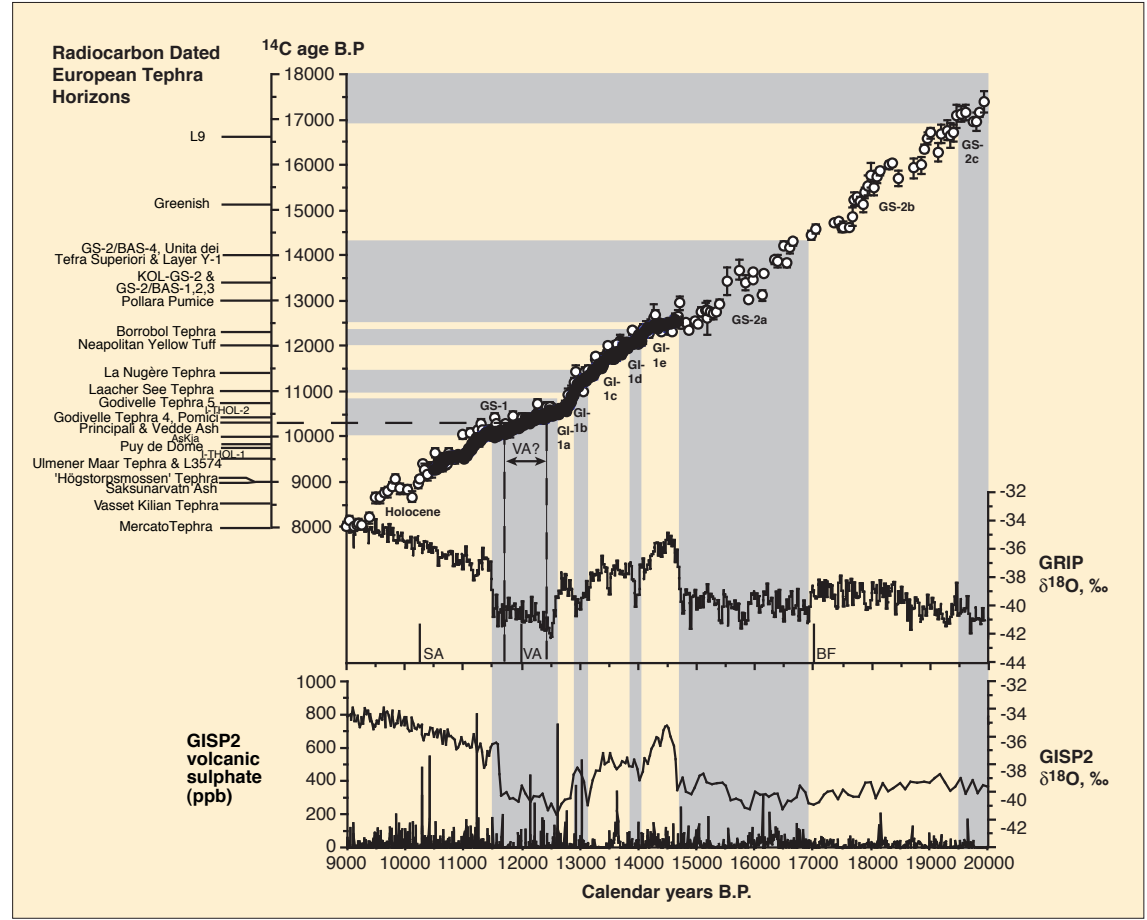

Fig. 1: Radiocarbon calibration curve for Termination 1 and the early Holocene, compared with GRIP and GISP2 $\delta^{18} \mathrm{O}$ stratigraphies (Stuiver and Grootes, 2000; Walker et al., 1999). The approximate positions of known European tephra horizons from this period are also indicated. The 'VA?' interval marks the interpolated calendar age range for the Vedde Ash according to the ${ }^{14} \mathrm{C}$ age calibration curve. Abbreviations for GRIP horizons: SA - Saksunarvatn Ash, VA - Vedde Ash, and BF - Black Feather tephra. Open circles: radiocarbon calibration data from Lake Suigetsu (Kitagawa and van der Plicht, 2000). Closed circles: radiocarbon calibration data from Cariaco Basin, assuming a marine reservoir age of $420{ }^{14} \mathrm{C}$ years (Hughen et al., 2000). Volcanic sulphate peaks are those reported by Zielinski et al. (1996).

of new methods (e.g., flotation and magnetic separation) for detecting tephra horizons invisible to the naked eye ('cryptotephra') undertaken by members of SCOTAV, the number and geographical extent of horizons has significantly expanded in a North Atlantic context. This raises the potential for a comprehensive tephrochronological framework that will allow high-precision correlation between geographically dispersed paleoclimatic and -environmental records and thereby test hypotheses of synchronous climate change, independent of known fluctuations in atmospheric radiocarbon content. Not all tephrochronological analyses, however, have been undertaken in the same way, or with the same analytical precision. For instance, electron microprobe analysis of tephra uses energy dispersive spectrometry (EDS) or wavelength dispersive spectrometry (WDS) to measure variations in the concentration of the oxides of the major elements within individual glass shards or mineral grains to characterize tephra horizons. WDS is the preferred method because it enables the relative importance of each major oxide to be monitored individually during analysis. This is particularly important with respect to the oxides of alkali metals, which are vulnerable to mobilization during analysis, though this can often be minimized or corrected for. For all results obtained using electron microprobes, the values are reported as percentages of sample weight. It is rare, however, for the total analysis to reach $100 \%$. In New 
Zealand and North America, for instance, it is routine to normalize the data to $100 \%$ (Shane, 2000), while in northern Europe it has been argued that no adjustment of the original measures should be undertaken (Hunt and Hill, 1993).

In order to optimize the potential of tephrochronological research, there is a need for improved analytical precision and for less ambiguous classification and terminology across the international scientific community. As a result of the above, SCOTAV has started a program to develop a protocol for improving analytical and reporting procedures, as well as for the establishment of a centralized database of tephra analyses (Turney et al., 2004). Full details can be found on the SCOTAV website at www.gns.cri.nz/inquatephra. Although originally aimed at Europe during the LastTermination, the protocol proposed here is of equal relevance to other regions and periods of interest. Such a protocol (Table 1) should include details about:

1.Stratigraphical Information

Contextual details should be provided about the site, including the stratigraphical context, the coring or other sampling methods employed, the sampling resolution/interval at which tephra were extracted, and whether tephra horizons are visible or traceable only as cryptotephra.

2.Information on Geochemical Procedures Adopted

Information should be supplied concerning the method(s) employed to extract tephra shards, on whether glass shards and other volcanic particles were heated above $350^{\circ} \mathrm{C}$, and the type of equipment and analytical procedures used to analyze the shards geochemically. SCOTAV also recommend that the results of geochemical analysis be presented in raw form, irrespective of which methodology is employed or which transformation (e.g., normalization) procedures are adopted, thus enabling re-calibration of the results in the event that revised protocols emerge in the future.
Table 1: Summary of stratigraphical, geochemical and dating criteria recommended by SCOTAV and for inclusion in a centralized tephra database.

\begin{tabular}{|l|}
\hline 1. Site location details \\
1.1 Name of site \\
1.2 Location - eight-figure latitude and longitude position \\
1.3 Location - national grid reference \\
1.4 Site context (open section, infilled lake basin, marine \\
sediment sequence, etc.) \\
1.5 Sampling procedures adopted (coring device used, \\
monolith tin, etc.) \\
2. Stratigraphical and sedimentological context \\
2.1 Sampling resolution adopted \\
2.2 Associated stratigraphical details (LOI data, \\
paleobotanical details, particle size analysis, etc.) \\
2.3 Visible horizon or cryptotephra \\
2.4 Dissemination of tephra through sequence (quantified \\
concentration data) \\
3. Tephra characteristics \\
3.1 Morphology of shards \\
3.2 Color and other surface characteristics (e.g., evidence of \\
alteration) \\
3.3 Mineralogical assemblages (if applicable) \\
3.4 Particle size data (where available) \\
3.5 Bedding features (if applicable) \\
4. Geochemical data \\
4.1. Extraction methods employed \\
4.2. Mineralogical analysis results \\
4.3. Geochemical procedures adopted (EDS, WDS, ICP- \\
AES, etc.) \\
4.4. Major oxide; REE; etc. (raw data) \\
4.5. Normalized and transformed data \\
4.6. Method of transformation \\
4.7. Glass standard(s) used and data \\
5.Age of tephra \\
4.1 Imported or direct-age estimate \\
4.2 Dating method(s) employed \\
4.3 Data and procedure used for calibration (if relevant) \\
4.4 Statistical uncertainty of age estimates \\
4.5 Materials used for dating \\
\end{tabular}

\section{Dating of Tephra Layers}

Where tephra layers have been dated using independent geochronological methods, the precise procedures and statistical uncertainties of the age estimates should be reported. Tephras can be dated directly (e.g., by fission track dating of the shards) or indirectly (e.g., by radiocarbon dating organic sediments adjacent to the tephra layers, or within which they occur). It is essential that the quality of the age estimates also be assessed and reported.

SCOTAV recommends that in future, the results of tephrochronological investigations be delivered to a regional archive. We propose that regional committees should be initiated throughout the world that develop their own comprehensive databases on behalf of the scientific community. In order to optimize the scientific value of the database, however, it is vital that the reporting of results should follow a systematic and comprehensive internationally agreed upon protocol. An initial draft of the analytical and contextual criteria that should be considered during investigations, and which should be addressed, is provided in Table 1. Few international journals will allow publication of such extensive reports within the main body of the text of a scientific paper and so recourse may need to be made to the use of condensed tables or appendices, and to electronic storage that will be accessible to the scientific community through the internet. Eventually, regional databases could be linked together, allowing the scientific community to access a global dataset. SCOTAV invites expressions of interest for the development of regional tephrochronological committees. The proposed new databases will be managed by a regional steering committee selected from these expressions of interest and the results will be freely available to all scientists with an interest in tephrochronology. We hope to establish the steering committees in early 2005 and their first task will be to consider feedback received on the matters discussed in this paper, and on the content and design of the proposed protocol for the reporting of results (Table 1). Recommendations concerning the draft protocol should be submitted to C.S.M.Turney (turney@uow.edu.au) by the closing date of 31 December 2004.

\section{REFERENCES}

Hunt, J.B. and Hill, P.G., 1993: Tephra geochemistry: a discussion of some persistent analytical problems. The Holocene, 3, 271-278.

Lowe, J.J., Hoek, W.Z. and INTIMATE group, 2001 Inter-regional correlation of palaeoclimatic records for the Last Glacial-Interglacial Transition: a protocol for improved precision recommended by the INTIMATE project group. Quaternary Science Reviews, 20, 1175-1187.

Shane, P., 2000: Tephrochronology: a New Zealand case study. Earth Science Reviews, 49, 223-259.

Turney, C.S.M. and Lowe, J.J., 2001: Tephrochronology. In W.M. Last and J.P. Smol (eds), Tracking Environmental Changes in Lake Sediments: Physical and Chemical Techniques. Kluwer Academic Publishers, Dordrecht, The Netherlands, 451-471.

Turney, C.S.M., Lowe, J.J., Davies, S.M., Hall, V., Lowe, D.J., Wastegård, S., Hoek, W.Z., Alloway, B., SCOTAV and INTIMATE members, 2004

Tephrochronology of Last Termination sequences in Europe: A protocol for improved analytical precision and robust correlation procedures (a joint SCOTAV-INTIMATE proposal). Journal of Quaternary Science, 19, 111-120. 